\title{
Indian Journal of Cardiovascular Diseases in Women: Charting a New Course!
}

\author{
Navya R. Alugubelli' Venkata M. Alla ${ }^{\circledR}$ \\ ${ }^{1}$ Department of Medicine, Medstar Health, Baltimore, Maryland, \\ United States \\ 2Division of Cardiovascular Diseases, Creighton University School of \\ Medicine, Omaha, Nebraska, United States \\ Ind J Car Dis Wom 2020;5:1-3
}

The Indian Journal of Cardiovascular Disease in Women $(I J C D W)$ has now entered its fifth year of publication, and we would like to extend our heartiest congratulations to the editorial board, publishers, patrons, contributors, and readers. The famous American singer Dolly Parton once said, "If you don't like the road you're walking, start paving another one." In publishing this journal, the editorial team has done just that. They have accomplished something that, to our knowledge, has not been done before, that is, publish a medical journal that is dedicated to cardiovascular disease (CVD) in women.

In the last two decades, India has undergone a major epidemiologic transition, with CVD emerging as the leading cause of morbidity and mortality. ${ }^{1,2}$ It is estimated that in India, CVD now accounts for 2.75 million deaths annually, which represents a quarter of all deaths and more than twothirds of deaths due to noncommunicable diseases. ${ }^{3}$ While CVD was traditionally thought to be a "man's disease," it is now abundantly clear that CVD is equally predominant in women and is, in fact, the leading cause of mortality. ${ }^{1-3}$ Notably, a greater proportion of women die from CVD compared with men and this gender inequity has been referred to as the "female disadvantage." 4,5

Clearly, the pathobiology of CVD in women is different from men in several aspects starting from risk factors to presentation, etiology, treatment response, and outcomes. Numerous novel risk factors that exclusively or predominantly impact women's risk of CVD such as adverse pregnancy outcomes, gestational diabetes, treatment for breast cancer, and autoimmune disorders have been identified. ${ }^{6}$ Furthermore, specific disorders such as coronary artery dissection, coronary embolism, microvascular angina, and myocardial infarction with normal coronary arteries predominantly afflict women. In addition, traditional risk factors such as smoking and diabetes appear to have a greater impact on CVD mortality in women compared with men. ${ }^{6}$ It is also known that presenting symptoms are different in women, with a greater proportion of them presenting with atypical chest pain or nonpain symptoms such as dyspnea, leading to delays in recognition and timely institution of effective therapies. In addition, a
Address for correspondence Venkata M Alla, MD, 7710 Mercy Road, Suite\# 401, Omaha, NE, 68124, United States (e-mail: venkataalla@creighton.edu).

long history of under representation of women in published CVD trials has led to a dearth of evidence on the comparative effectiveness of standard treatment pathways in women compared with men. ${ }^{7}$

Apart from the numerous biologic and pathophysiologic differences, there is now a robust body of evidence that suggests that socioeconomic and cultural factors contribute significantly to the gender inequities in CVD outcomes. These include income level, educational attainment, employment status, and environment. These factors impact women to a greater extent than men even in high-income countries with universal health coverage. ${ }^{8,9}$ Given the existing social norms (patriarchal society), large rural population with limited access to healthcare, lower literacy and financial independence among females, the impact of socio economic factors on CVD outcomes women is likely more pronounced in India. ${ }^{10,11}$ In one large study from a tertiary referral center in India, the sex ratio for attendance in an outpatient clinic was 1.7 favoring males, suggesting that men were $70 \%$ more likely than women to seek and receive healthcare, resulting in the so called "dilemma of the missing women." ${ }^{2}$

In addition to all the aforementioned factors, emerging evidence has demonstrated that human factors such as unconscious physician bias and physician-patient gender incongruence impact delivery of care and cardiovascular outcomes of women and minorities. ${ }^{13-15}$ As with socioeconomic factors, the impact of physician-patient gender discordance appears to be more pronounced in women who are treated by male physicians compared with men treated by female physicians. ${ }^{16}$ Proposed reasons for these observations include better communication and counselling, patient-centered approach and better adherence to clinical guidelines by female physicians compared with their male counterparts. While medical school enrollment for women has increased significantly and has exceeded that of men in the last few years, a significant gender gap persists in postgraduate (MD and MS programs) and superspecialty training (DM programs). ${ }^{17}$ Of the estimated 4,000 cardiologists in India, less than $15 \%$ are women. ${ }^{18,19}$ The reasons for this are likely multifactorial with some related to the training environment
DOI https://doi.org/ 10.1055/s-0040-1709373.
(C)2020 Women in Cardiology and Related Sciences
License terms

(1) $\Theta \circledast$ 
such as lack of female role models in cardiology, potential for harassment, and discrimination in training environment, while others may be related to practice patterns such as challenges in finding part-time cardiology jobs or lack of flexibility in schedules, etc. Yet other factors may be societal such as the expectation that women should take up a greater burden of child raising and homemaking. Therefore, the lack of adequate number of women in cardiology can have a direct bearing on the cardiovascular health of women and efforts to address this imbalance should be taken up in earnest by the cardiology community, academia, and training programs.

In a country with close to 630 million females, and more than one million CVD-related deaths in women annually, policymakers, the scientific community, and the society at large can no longer afford to remain complacent. It is no longer just a moral or ethical obligation but a financial imperative to address these disparities both in India and across the world. Against this backdrop, the successful completion of 5 years of publication of IJCDW is a giant leap forward and should be celebrated. To our knowledge, there is no other journal that is exclusively focused on cardiovascular disease in women. In a country, where a woman cardiologist (Dr. S. Padmavati) is credited with starting the first formal cardiology training program, ${ }^{20}$ this is another first and a fitting testament to the enterprising spirit and leadership of Indian women cardiologists. One cannot help but notice that a majority of the editorial board members and the Chief Editor are accomplished women, and this in itself is a bold statement of the journal's vision that deserves recognition of the highest order. In contrast, a recent study of the editorial board composition of leading European and North American cardiology journals concluded that there were no women editors-in-chief for US general cardiology journals and only one woman editor-in-chief for a general European cardiology journal between 1998 and 2018. ${ }^{21}$

Finally, to be truly transformative, the journal should expand its horizons beyond just the pathophysiologic uniqueness of CVD in women and commit itself to (1) highlighting research on gender inequalities in CVD care and ideas that can mitigate these inequities; (2) serving as a scientific platform and voice for issues relevant to women in cardiology (both in training and practice) and promoting inquiry into methods to address them; (3) providing a platform/pathway for academic advancement of women in cardiology by facilitating networking, mentorship, leadership, and opportunities in medical publishing and editorship for next generation of women cardiologists in India. This will not only ensure the relevance of this journal for many years to come but make it a catalytic engine for change and innovation in equitable healthcare delivery and medical education in India. While the vision and publication of IJCDW is just one step in the right direction, it clearly charts a new course that will hopefully inspire many to follow. In the words of Ruth Bader Ginsburg, "Women belong in all places where decisions are being made... It shouldn't be that women are the exception."

\section{Conflict of Interest}

None declared.

\section{References}

1 India State-Level Disease Burden Initiative CVD Collaborators. The changing patterns of cardiovascular diseases and their risk factors in the states of India: the global burden of disease study 1990-2016. Lancet Glob Health 2018;6(12):e1339-e1351

2 Benjamin EJ, Muntner P, Alonso A, et al; American Heart Association Council on Epidemiology and Prevention Statistics Committee and Stroke Statistics Subcommittee. Heart disease and stroke statistics-2019 update: a report from the American heart association. Circulation 2019;139(10):e56-e528

3 Prabhakaran D, Jeemon P, Roy A. Cardiovascular diseases in India: current epidemiology and future directions. Circulation 2016;133(16):1605-1620

4 Global Health data exchange. Available at: http://ghdx. healthdata.org/gbd-results-tool? params=gbd-api-2017-permalink/c776a51abacc0d19b9c44b7328b071eb. Accessed on February 24, 2020

5 Woodward M. Cardiovascular disease and the female disadvantage. Int J Environ Res Public Health 2019;16(7):E1165

6 Garcia M, Mulvagh SL, Merz CN, Buring JE, Manson JE. Cardiovascular disease in women: clinical perspectives. Circ Res 2016;118(8):1273-1293

7 Scott PE, Unger EF, Jenkins MR, et al. Participation of women in clinical trials supporting FDA approval of cardiovascular drugs. J Am Coll Cardiol 2018;71(18):1960-1969

8 Schultz WM, Kelli HM, Lisko JC, et al. Socioeconomic status and cardiovascular outcomes: challenges and interventions. Circulation 2018;137(20):2166-2178

9 Fabreau GE, Leung AA, Southern DA, et al. Sex, socioeconomic status, access to cardiac catheterization, and outcomes for acute coronary syndromes in the context of universal healthcare coverage. Circ Cardiovasc Qual Outcomes 2014;7(4):540-549

10 Asfaw A, Lamanna F, Klasen S. Gender gap in parents' financing strategy for hospitalization of their children: evidence from India. Health Econ 2010;19(3):265-279

11 Chow CK, Patel AA. Women's cardiovascular health in India. Heart 2012;98(6):456-459

12 Kapoor M, Agrawal D, Ravi S, Roy A, Subramanian SV, Guleria R. Missing female patients: an observational analysis of sex ratio among outpatients in a referral tertiary care public hospital in India. BMJ Open 2019;9(8):e026850

13 Daugherty SL, Blair IV, Havranek EP, et al. Implicit gender bias and the use of cardiovascular tests among cardiologists. J Am Heart Assoc 2017;6(12):e006872

14 Greenwood BN, Carnahan S, Huang L. Patient-physician gender concordance and increased mortality among female heart attack patients. Proc Natl Acad Sci U S A 2018;115(34):8569-8574

15 Tsugawa Y, Jena AB, Figueroa JF, Orav EJ, Blumenthal DM, Jha AK. Comparison of hospital mortality and readmission rates for Medicare patients treated by male vs female physicians. JAMA Intern Med 2017;177(2):206-213

16 Baumhäkel M, Müller U, Böhm M. Influence of gender of physicians and patients on guideline-recommended treatment of chronic heart failure in a cross-sectional study. Eur J Heart Fail 2009;11(3):299-303

17 Curtis AB, Rodriguez F. Choosing a career in cardiology: where are the women? JAMA Cardiol 2018;3(8):691-692 
18 Younus Ahmad Dar. Available at: https://m.siliconindia.com/ news/career/The-Glaring-Case-of-Indian-Medical-EcosystemMore-Female-Medical-Graduates-but-Less-Female-Doctorsnid-205422.html. Accessed on February 25, 2020

19 KhannaR. Available at: https://www.acc.org/membership/ sections-and-councils/women-in-cardiology-section/section-updates/2019/04/17/14/22/taking-the-road-less-traveled. Accessed on February 24, 2020
20 Bhadra M. Indian women in medicine: an enquiry since 1880. Indian Anthropologist 2011;41:17-43

21 Balasubramanian S, Saberi S, Yu S, Duvernoy CS, Day SM, Agarwal PP. Women representation among cardiology journal editorial boards. Circulation 2020;141(7):603-605 